\title{
"A Gift, An Obligation": Produced by the American Academy of Pediatrics with narration by Cliff Robertson
}

\author{
CHARLES U. LOWE \\ Office of the Assistant Secretary for Health, Washington, D.C., USA
}

I am here to represent the American Academy of Pediatrics (AAP), and I am pleased to do so because I believe it is important for us to recognize the contribution that practicing physicians, physicians in private practice, have made and continue to make in improving immunization levels among our children.

Occasionally, those of us in Washington need to be reminded that well over $90 \%$ of the children in this country receive health care and approximately half receive immunization from the private sector.

The film you are about to see was produced by the Academy with a grant from the Division of Health Information Services, Merck Sharp \& Dohme. It is an excellent example, in my judgment, of the ways in which the private sector has responded creatively to the need for greater public awareness regarding immunization.

The Academy's public information effort goes back more than 6 years when the AAP began releasing public service television spots on the need for complete childhood immunization.

The Academy, along with Merck Sharp \& Dohme and other industry sponsors, was also in the forefront of the Immunization Action Month Program. The AAP effort drew heavily on creative and financial resources from companies like Merck, and on the goodwill and prestige of organizations like the Academy.

The AAP, in fact, for several years coordinated the health information activities of all the medical societies involved in the Immunization Action Month Program.
The AAP has developed extensive policy statements about the need for immunization, saying that a national immunization policy which eliminates financial barriers to immunization and encourages immunization as a part of total preventive health care service, is essential.

The Academy produces wallet-size immunization records and informational flyers to help its members spread the immunization message.

During the year 1979, the AAP will be seeking to raise America's consciousness regarding childhood health care problems through a national program called "Speak Up For Children." A major part of this program will be enacted on the part of individual state chapters to raise childhood immunization levels through public information programs and enforcement of state immunization laws.

The film we are about to see is called "A Gift, An Obligation." Since it began distribution in January, it has enjoyed unprecedented success. The film has been very popular with broadcasters, receiving a total of 92 telecasts on 79 stations, reaching a voice that is estimated at more than 6 million people. In addition, the film has been booked by nearly 800 church groups, hospitalization and health organizations, schools, and community action groups. Nearly 14,000 other such groups have purchased a copy of the film at cost for their own use. I think we should congratulate the Academy and Merck Sharp \& Dohme on the success of the film. 